\title{
Extreme airborne asbestos concentrations in a public building
}

\author{
Eliezer Ganor, Alf Fischbein, Shmuel Brenner, Paul Froom
}

\begin{abstract}
Fibre concentrations of asbestos were measured in the air of a communal dining room in which the damaged ceiling had a sprayed on coating of insulation containing asbestos. The average concentration of crocidolite asbestos fibres was $4 \mathrm{f} / \mathrm{cm}^{3}, 20$ times the highest air concentration that appears to have been reported previously for a public building. It is concluded that although air concentrations of asbestos fibres in public buildings containing asbestos insulation materials are usually low, high concentrations can occur. This may have implications for the risk of exposed persons developing diseases associated with asbestos.
\end{abstract}

The potential health risk associated with the presence of asbestos fibres in the air of public buildings and schools is currently a topic for debate. ${ }^{12}$ Recent risk estimates for developing lung cancer and mesothelioma from continuous exposure to very low concentrations of asbestos fibres have been made to determine the public health hazard outside the workplace. ${ }^{34}$ Calculations of lifetime risks have generally resulted in extremely low values. ${ }^{3-5}$ It has been argued that the costs of removing materials containing asbestos from public buildings, estimated at between $\$ 100$ and $\$ 150$ billion dollars in the United States, may outweigh the potential health benefits. ${ }^{56}$

In public buildings, the assessments of risks are generally based on low concentrations of crysotile asbestos fibres measured previously, ${ }^{7}$ the highest values averaging $0.2 \mathrm{f} / \mathrm{cm}^{3.8}$ The present report was prompted by our finding of very high concentrations of asbestos fibres in the air of the dining room of a communal settlement (kibbutz).

Institute for Environmental Research, Ministry of the Environment, Sackler Faculty of Medicine, Tel Aviv University, Ramat Aviv, Tel Aviv 69978, Israel E Ganor, S Brenner, P Froom

Institute for Occupational Health, Sackler Faculty of Medicine, Tel Aviv University, Ramat Aviv, Tel Aviv 69978, Israel

A Fischbein

\section{Case study}

In 1970, the interior ceiling of the dining room of a kibbutz was insulated by spraying on insulation material containing asbestos. The communal dining room covers an area of $200 \mathrm{~m}^{2}$ with open windows allowing free access to birds. The birds often cling to the ceiling by their claws causing damage to the insulation. Over the years, the asbestos layer began to fragment. Five years before our measurements physical deterioration and fragmentation of the material was clearly evident.

After concern was expressed by some of the members of the settlement, the present investigation was conducted by the Institute for Environmental Research of the Ministry of the Environment.

\section{Methods}

Sampling and analysis were carried out according to the recommended technical method No 2 (RTM-2), which was issued by the Asbestos International Association (AIA). ${ }^{9}$ Briefly, dust particles were collected for eight hours on $0.8 \mu \mathrm{m}$ nucleopore filters precoated with gold. These were maintained 1.5 metres above ground and had a flow rate of $8.0 \mathrm{l} / \mathrm{min}$. The samples were again coated with gold and analysed by a scanning electron microscope equipped with an energy dispersion system. Four separate samples were collected. Some of the previous measurements used for comparison were analysed by phase contrast microscopy (RTM-1). ${ }^{10}$

\section{Results}

Table 1 shows the results of the air measurements.

Table 1 Average asbestos fibre concentrations measured in various environments in Israel

\begin{tabular}{lll}
\hline Location & $\begin{array}{l}\text { Concentration } \\
\left(\mathrm{f} / \mathrm{cm}^{3}\right)\end{array}$ & $\begin{array}{l}\text { Method of } \\
\text { analysis }\end{array}$ \\
\hline Dining room (kibbutz) & $4 \cdot 0$ & RTM1, RTM2 \\
Asbestos cement plant & $0 \cdot 14$ & RTM1 \\
Asbestos cement plant dump site & 0.02 & RTM2 \\
Garage brake cleaning & 0.02 & RTM2 \\
Highway & 0.002 & RTM2 \\
\hline
\end{tabular}

*Yearly average in 1984 taken from 122 work stations (682 samples; see ${ }^{17}$ ). 


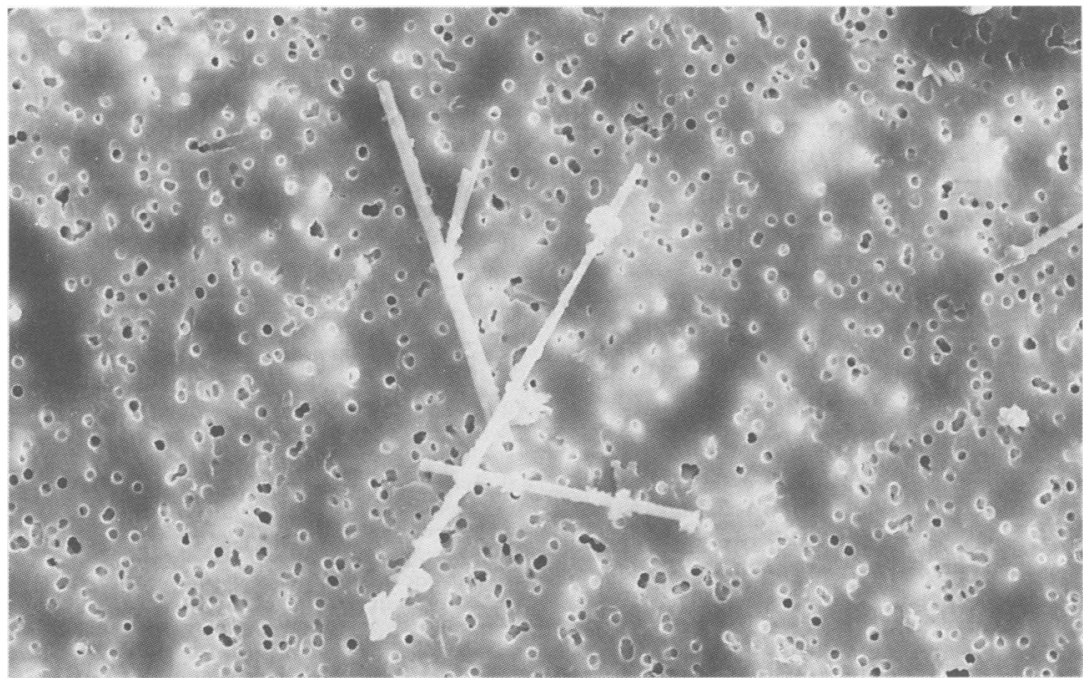

Electron micrograph of typical crocidolite fibres containing the elements $\mathrm{Na}, \mathrm{Si}$, and $\mathrm{Fe}$ as measured on a $0.8 \mu \mathrm{m}$ nucleopore filter.

Also given, for comparison, are asbestos fibre concentrations measured in the ambient air in and around an asbestos cement plant, at a highway, in a garage where brake linings containing asbestos are repaired, and around a dump site where waste from the asbestos cement plant was placed. The concentrations in the air of the dining room ranged from 3 to $5 \mathrm{f} / \mathrm{cm}^{3}$ and were significantly higher than the concentrations in air measured at the comparison sites. The asbestos fibres from the dining room showed the typical spectrum of crocidolite asbestos (figure).

Table 2 gives the maximum concentrations reported previously in public buildings. The concentrations in the communal dining room were 20 times higher than the highest concentration previously reported $^{8}$ and more than 120 times those reported by all other authors. ${ }^{71-13} \mathrm{We}$ have subsequently identified another public building where a ceiling in poor condition with sprayed on materials containing asbestos also resulted in high concentrations of crocidolite fibres $\left(3 \mathrm{f} / \mathrm{cm}^{3}\right)$.

Table 2 Maximal asbestos fibre concentrations reported in various public buildings

\begin{tabular}{lll}
\hline Reference & Year & $\begin{array}{l}\text { Concentrations } \\
\left(\mathrm{f} / \mathrm{cm}^{3}\right)\end{array}$ \\
\hline Present report $_{\text {Pinchin }^{8}}$ & 1991 & $4 \cdot 0$ \\
Chesson et al $_{\text {Burdett and Jeffrey }}{ }^{13}$ & 1982 & 0.202 \\
Chatfield $^{12}$ & 1990 & 0.033 \\
& 1986 & 0.013 \\
\hline
\end{tabular}

The present report used scanning electron microscopy. The others used transmission electron microscopy.

\section{Comment}

We found unusually high exposure to airborne asbestos fibres in a public building, much higher than previously reported. Pinchin ${ }^{8}$ collected samples in 13 buildings in Ontario, Canada, after exclusion of school buildings and buildings that were damaged. Thus it is conceivable that other buildings may have had higher concentrations than the maximum concentration of asbestos fibres of $0.2 \mathrm{f} / \mathrm{cm}^{3}$ reported in that study. On the other hand, the maximum concentration found by Chesson et al in 49 governmentowned buildings, including 37 buildings with damaged asbestos containing materials, was only $0.013 \mathrm{f} / \mathrm{cm}^{3}$.

Our results should be interpreted with caution. Data by other authors presented in table 2 were obtained by transmission electron microscopy (TEM), whereas we used scanning electron microscopy (SEM). The sensitivity of the two methods, however, is thought to be similar, although we are unaware of studies comparing the two methods. Furthermore, the extremely high concentrations found in the dining room were much higher than those found at other sites in Israel using the same methodology (SEM). Thus it appears that our findings are exceptional.

Our findings are also remarkable in that crocidolite was the type of asbestos used in the insulation material. Despite the fact that in Israel and in the United Kingdom the use of crocidolite in sprayed on asbestos is not unusual, most reports on airborne asbestos fibres in buildings do not consider this fibre type in their assessment of risk.

It should be noted that due to its carcinogenic 
nature and the lack of a known threshold above which adverse health effects occur, no air quality standard has been set for the concentration of asbestos fibres in the general environment, ${ }^{14}$ or as an indoor air pollutant. ${ }^{15}$ Nevertheless the Israel Governmental National Committee for Hazardous Dusts recently adopted a guideline value of $0.0016 \mathrm{f} / \mathrm{cm}^{3}$ to serve as the basis for policy decisions regarding findings from the monitoring of the general environment as well as from indoor concentrations in public buildings. ${ }^{16}$ The value of $4 \mathrm{f} / \mathrm{cm}^{3}$ detected in the communal dining room far exceeds the guideline value and may have resulted in a health hazard to the exposed population. Immediately after our test results, asbestos was removed from the dining room. Because of the high air concentration of crocidolite asbestos found, a health survey of potentially exposed persons is being considered.

We conclude that very high exposure to airborne asbestos fibres can indeed occur in public buildings. The building type described in this case study is rarely examined in surveys of public buildings in many industrialised countries primarily because of differences in climate and thereby related construction needs. It may be that indoor asbestos insulation materials used in settings similar to those described in this report could result in air concentrations that are significantly higher than those found in most published reports. Thus the environment characterised by us in this case study may constitute an exposure source to be considered in future epidemiological studies. Although there is widespread concern over exposure to asbestos, little information is available about asbestos concentrations in buildings. ${ }^{17}$ Our findings suggest that further environmental assessment and air measurements in buildings in which damaged insulation materials containing asbestos are present are warranted.
1 Mossman BT, Bignon J, Corn M, Seaton A, Gee JBL. Asbestos: scientific developments and implications for public policy. Science 1990;247:294-301.

2 Brody AR. Asbestos, carcinogenicity and public policy. Science 1990;247:795 (letter).

3 Hughes JM, Weill $\mathrm{H}$. Asbestos exposure-quantitative assessment of risk. Am Rev Respir Dis 1986;133:5-13.

4 Weill $\mathrm{H}$, Hughes JM. Asbestos as a public health risk: disease and policy. Annu Rev Public Health 1986;7:171-92.

5 Mossman BT, Bee JBL. Asbestos-related diseases. N Engl J Med 1989;320:1721-30.

6 Corn $M$. Perspective on the potential risk and management options for asbestos in buildings. Presented at the international occupational lung association meeting, Montreal, 1986.

7 Chesson J, Hatfield J, Schultz B, Dutraw E, Blake J. Airborne asbestos in public buildings. Environ Res 1990;51:100-7.

8 Pinchin DJ. Asbestos in buildings Study No 8. Toronto, Ontario: Royal Commission on Matters of Health and Safety arising from the use of asbestos, 1982.

9 Asbestos International Association (AIA). Health and safety publications, recommended technical method No 2 (RTM-2). London: Health and Safety Publications, 1984.

10 Asbestos International Association (AIA). Health and safety publications, recommended technical method No 1 (RTM-1). London: Health and Safety Publications, 1988

11 US Environmental Protection Agency. Guidance for assessing and managing exposure to asbestos in buildings. Washington DC: USEPA, 1986. (Seventh draft report contract 68-02-4243.)

12 Chatfield EJ. Airborne asbestos levels in Canadian public buildings. In: Chatfield EJ, ed. Asbestos fiber measurements in building atmospheres. Mississauga: Ontario Research Foundations, 1986.

13 Burdett GJ, Jaffrey SAMT. Airborne asbestos concentrations in buildings. Am Occup Hyg 1986;30:185-99.

14 World Health Organisation. Air quality guidelines for Europe. Asbestos European Series No 23. Geneva: WHO, 1987:26-30 and $182-99$.

15 World Health Organisation. Indoor air pollutants: exposure and health effects. European reports and studies 78 . Geneva: WHO, 1982:1-42.

16 Brenner S, Ganor E, Anavi Z. Asbestos fibres in the ambient air of Israel. Environmental Management and Health. An International Journal 1990;1:13-6.

17 Wasserman M, Naim L, Lemesch C. Research and prevention of asbestos-related diseases in Israel. In: Peters GA, Peters BJ, eds. Asbestos medical research Vol 4. Legal and engineering aspects. Sourcebook on asbestos diseases: medical. New York: Garland Law Publishing, 1989:488.

Accepted 4 November 1991 